\title{
Téoros
}

Revue de recherche en tourisme

\section{Voyage en pays atikamekw Impressions}

\section{Marie-Andrée Boucher}

Volume 17, numéro 2, été 1998

L'industrie touristique autochtone

URI : https://id.erudit.org/iderudit/1072280ar

DOI : https://doi.org/10.7202/1072280ar

Aller au sommaire du numéro

\section{Éditeur(s)}

Université du Québec à Montréal

\section{ISSN}

0712-8657 (imprimé)

1923-2705 (numérique)

Découvrir la revue

\section{Citer ce document}

Boucher, M.-A. (1998). Voyage en pays atikamekw : impressions. Téoros, 17(2), 46-47. https://doi.org/10.7202/1072280ar d'utilisation que vous pouvez consulter en ligne.

https://apropos.erudit.org/fr/usagers/politique-dutilisation/ 


\section{VOYAGE EN PAYS ATIKAMEKW}

\section{IMPRESSIONS}

\section{Marie-Andrée Boucher}

\section{En compagnie des membres d'Atoka, fin octobre 1994}

Enfoncée dans mes lainages, le nez dans mon foulard, la tuque rabattue sur les yeux, je me laisse emporter dans un bateau qui avance tumultueusement vers le pays atikamekw. L'eau gicle de partout et nous nous regardons en souriant en cette superbe matinée d'automne. Impossible de parler dans le vacarme, alors nous nous concentrons sur le paysage, fragments d'îles posées sur une eau de velours, forêts de conifères et caps de roche brute avec, ça et là, quelques chalets perdus qui nous font bien envie.

\section{DE L'IMPOSSIBLE VOYAGE}

Je pense à hier, à cette Thérèse, discrète, efficace, souriante, qui nous a accueillis si gentiment, qui, en complotant avec Roselyne, nous a préparé cet impossible voyage sur une terre presque inconnue, celle de son peuple. Car, bien qu'enfant de la même terre, puisque les épinettes et les lacs d'Abitibi sont les sæurs et les frères de ceux de Haute-Mauricie, je reste à peu près ignorante de ce monde que j'ai pourtant côtoyé, celui des premières nations.

Bien sûr, je sais qu'il y a onze nations autochtones au Québec ; je sais quel rôle essentiel elles ont joué dans l'établissement de la Nouvelle-France, comment elles nous ont livré quelques secrets sếculaires pour nous permettre de " passer l'hiver $"$, comment elles nous ont guidés au fil des rivières dans le fantastique pays d'alors. J'ai aussi une petite idée des difficultés qu'elles traversent actuellement, je connais certains des conflits qui les opposent aux * blancs $*$; mais elles, je les connais à peine.

C'est pourquoi j'attache tellement d'importance à l'impossible voyage ; c'est pourquoi j'ai été si touchée par la petite réception que nous avait préparée hier, avec ses collègues, ses amis, ses parents et même le maire de La Tuque, notre marraine atikamekw, Thérèse. Premiers contacts timides avec ceux qui vivent en dehors des communautés, en " ville $*$, pour finir en dansant le macoucham... à la file indienne.

Mais pour l'heure, je m'en vais par les chemins d'eau, vers un lieu dont seul le nom est une belle promesse de dépaysement : Coocoocache. Au loin, debout dans une embarcation, nous apercevons une silhouette. C'est Jacques Néwashish, dit Roselyne. Est-il venu là pour nous attendre ? Je ne sais pas. Je me contente d'examiner, maintenant que nous sommes à côté, cet homme impressionnant tant la sagesse émane de sa personne. Il a des gestes précis qui semblent lents aux occidentaux stressés que nous sommes. La réalité est tout autre : nous abordons la plénitude. Le voilà, enfin, ce Coocoocache, petit bout de terre perdu et isolé, presqu'île sauvage, beau pays humain.

Sur le quai, des mains puissantes agrippent le bateau. On nous souhaite la bienvenue. Encore un peu engourdis, patauds, nous montons le sentier avec les bagages. Le campement apparaît. Entre les sapins et les bouleaux blancs, une dizaine de tentes de $\approx$ prospecteurs $*$ plantées solidement dans le sol odorant, telles que les Amérindiens et les coureurs des bois modernes (prospecteurs, géologues, trappeurs) les utilisent aujourd'hui, plus grandes, plus commodes, plus faciles à chauffer. Il y a bien un tipi, là-bas, autour duquel s'amusent des enfants.

Jacques nous explique que c'est la semaine culturelle, moment où les enfants partent en forêt avec leurs parents et leurs grandsparents pour reprendre contact avec la vie traditionnelle et leur culture. Jadis, les familles s'enfonçaient en forêt l'hiver durant pour la trappe. Plus possible maintenant à cause de l'école. Un pan de quotidien surgit : il y a la vie dans la communautế, calquée sur le rythme nordaméricain, et il y a la vie dans les bois, sans aucune commune mesure, la seule vraie demeure des Atikamekw.

Nous le sentons bien, ici, nous sommes dans leur élément, dans leur monde, celui avec lequel ils communient depuis toujours. Et, formidable antagonisme, Jacques est revenu occuper Coocoocache abandonné pour y monter des projets socioculturels, dont l'accueil de jeunes décrocheurs qui, en participant à l'érection de ce lieu traditionnel, retrouveront la confiance et la motivation qui leur manquent pour poursuivre leurs études.

Ce seront deux belles journées chez les gens de Coocoocache, où il fera bon et doux, où nous nous sentirons si bien que ce sera dur de partir. 

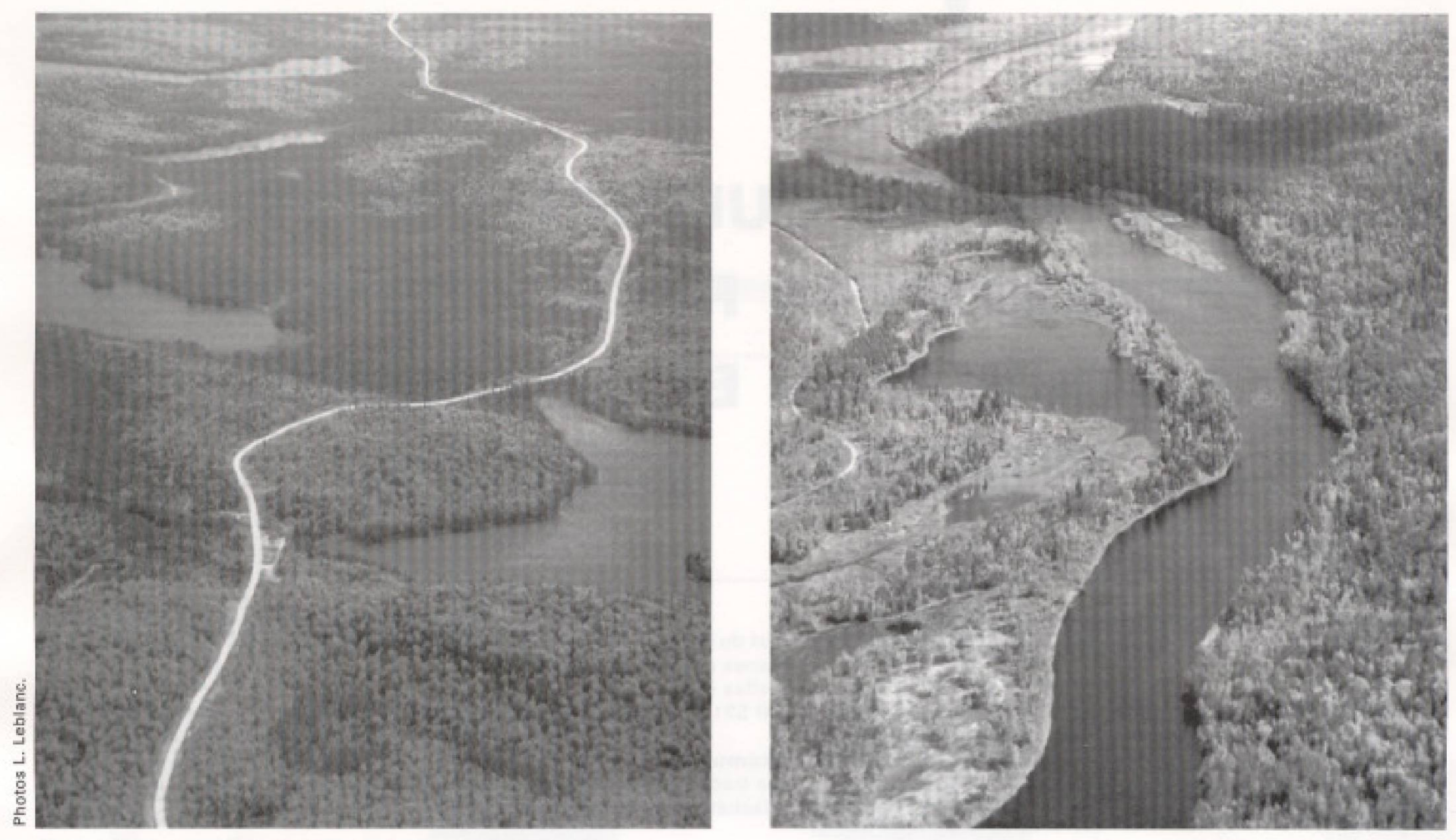

Vues aćriennes de la Haute-Mauricie, territoire atikamekw.

Après une nuit à dormir dans le "sapinage $\%$, les pieds tout près du poêle à bois ronflant, nous reprenons le bateau puis piquons à travers bois pour Manouane. C'est comme si je n'avais jamais vu le dedans du Québec. Des chemins forestiers interminables et, en plein milieu de nulle part, quelques tentes de prospecteurs. Le bois semble impénétrable, mais il n'est pas aussi désert que cette route le laisse croire. Puis Manouane, quelques milliers d'habitants, une école, une église, un restaurant où nous attendent les membres importants de la communauté. Encore des petites hésitations avant les moments magiques où les conversations se détendent. Étonnés, nous le restons, par tant de générosité dans l'hospitalité. Le lendemain, nous rencontrons dans le village nos nouveaux amis vaquant à leurs occupations dans les domaines sociaux et scolaires. Des gens comme les autres, semblerait-i1, mais pas tout à fait, car ce soir-la, nous sommes chez David Marcel Ottawa. David a fait de son campement familial un lieu d'accueil unique où viennent des visiteurs d'ici ou d'ailleurs pour un séjour. Interprétation de la culture atikamekw sur le site traditionnel, pêche, randonnée pédestre, repas plantureux préparés par Marie, et le simple bonheur d'être là, comme en famille, dans son grand $*$ camp $*$ en bois.

C'est la brunante ; nous nous préparons au repas du soir et les voilà qui surgissent dessus les îlots - habillés comme des ours car le froid est tombé sur le lac tout naturellement après leur journée de travail au bureau. Ils ont amené leur repas et tout s'organise très simplement ; nous mangeons et puis nous allons au feu, car ils ont amené les tambours. Et là se termine l'impossible voyage, dans le crépitement du feu de bois, dans l'air craquant du soir, dans l'éclair jaune que lance la flamme sur les visages des Atikamekw qui chantent pour nous.

\section{DE LA RENCONTRE, DE L'ÉCHANGE}

Leur accueil est généreux ; non pas par l'effusion, mais par le respect et l'ouverture à d'autres cultures. Patiemment, très gentiment, ils répondent à toutes nos questions. Après les premiers moments de contacts (précédés parfois de cérémonies, de discours, d'explications), les rires qui fusent et les premiers échanges culturels, nous leur chantons une petite chanson française (enfin j'essaie de me joindre au chour), et ils nous font l'immense privilège de chanter accompagnés du tambour. Au regard de ce que signifie vraiment pour eux cet émouvant chant guttural, sorti tout droit des entrailles de la terre, de ce que représente le tambour, dont le rythme s'accorde aux pulsations du monde, pas le nôtre, celui des rè̀gnes animal, végétal et minéral, nous avons reçu beaucoup plus que nous avons donné. Toujours.

Il suffisait de nous ouvrir, d'écarquiller les yeux, de tendre la main pour attraper tout ce qui était à notre portée, et il y en avait plus que nous pouvions en prendre. Ces quelques jours furent si courts et si intenses. Nous en sommes sortis muets d'émotion (quel exploit, mes amis !) dans un trop-plein dont la digestion allait se faire encore pendant quelques mois.

Que vous dire de plus, sinon humblement, merci, et c'est si peu. Merci à ceux qui sont à l'origine de ce voyage, merci à ceux qui nous ont reçus. Kwé Kwê.

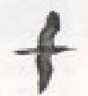

